\title{
Association between maternal high-risk fertility behavior and anemia among reproductive age women in Ethiopia
}

Noha Fadl ( $\square$ nohaosama@alexu.edu.eg)

Alexandria University High Institute of Public Health https://orcid.org/0000-0001-9807-2720

\section{Zelalem T. Haile}

Ohio University Heritage College of Osteopathic Medicine https://orcid.org/0000-0002-2912-8564

Gillian H. Ice

Ohio University Heritage College of Osteopathic Medicine

\section{Research article}

Keywords: Anemia, mother's age at delivery, birth order, birth interval, Demographic and Health Survey, Ethiopia

Posted Date: March 3rd, 2020

DOI: https://doi.org/10.21203/rs.3.rs-15729/v1

License: (a) (1) This work is licensed under a Creative Commons Attribution 4.0 International License. Read Full License 


\section{Abstract}

Objectives Anemia constitutes a major public health problem in low- and middle-income countries. The purpose of this study was to examine the individual and combined influence of high-risk fertility behavior on anemia among reproductive age women in Ethiopia.

Methods Secondary data analysis was conducted using a nationally representative sample of women aged 15-49 years from the 2016 Ethiopia Demographic and Health Survey $(n=5799)$. Anemia status was the outcome of interest. Maternal high-risk fertility behaviors were measured using maternal age at delivery, birth order and birth interval. Descriptive statistics and multivariable regression models were performed.

Results Overall, $28.7 \%$ of women had anemia and $71.4 \%$ experienced at least one high-risk fertility behavior. In the multivariable model, there was a significant interaction between high-risk fertility behavior and place of residence on anemia. Women with any high-risk fertility behavior were more likely to have anemia than women without any high-risk fertility behavior. However, the strength of association differed by place of residence (AOR: 2.68; $95 \% \mathrm{Cl}, 1.26-5.67$ for urban and AOR: 1.27; $95 \% \mathrm{Cl}, 1.01-1.61$ for rural residents). Single high-risk fertility behavior was significantly associated with anemia only among urban residents (AOR: $2.65 ; 95 \% \mathrm{Cl}, 1.20-5.83$ ). Multiple high-risk fertility behavior significantly increased the odds of anemia, with stronger association among urban residents (AOR: 2.82; 95\% Cl, 1.14-6.95) than rural residents (AOR: 1.56; $95 \% \mathrm{Cl}, 1.11-2.19$ ).

Conclusions Place of residence moderated the relationship between high-risk fertility behaviors and anemia. Our findings suggest the need for context-specific strategies and interventions to prevent anemia.

\section{Introduction}

Anemia, or low concentration of hemoglobin, constitutes a major public health problem in low- and middle-income countries (LMICs) with significant consequences for human health as well as social and economic development [1]. It affects over 528 million women of reproductive age worldwide; of which $38 \%$ occur in Africa. It is estimated that $29 \%$ of non-pregnant women (496 million) and $38 \%$ of pregnant women (32 million) have anemia [2]. As a low-income country, Ethiopia shares the burden of the problems of anemia. According to WHO report in 2011, the prevalence of anemia in Ethiopia is 19\% and $23 \%$ for non-pregnant and pregnant women, respectively [2].

Anemia is considered as largely preventable and easily treatable, and strategies for its prevention and control are well documented. However, it remains a common cause of morbidity and mortality [3]. Anemia in women adversely affects both their productive and reproductive capabilities [1]. Anemia contributes to approximately $20 \%$ of maternal deaths [4]. Thus, reducing anemia is recognized as an important component of women's health, and becomes the second global nutrition target for 2025 calls for a $50 \%$ reduction of anemia among reproductive age women [5]. 
Previous studies have identified several socio-demographic, economic and nutritional risk factors of anemia, specifically among women of reproductive age $[6,7]$. Maternal high-risk fertility behavior, broadly in the form of too early or too late childbearing age, closely spaced birth and too many births, is one of the bio-demographic risk factors that could affect women's health. In Ethiopia, childbearing begins early. More than one-third (34\%) of women age 20-49 give birth by age 18 and $11 \%$ of adolescent girls age 15-19 are already mothers or pregnant with their first child. Additionally, Ethiopia has a high level of parity, and one in five births (20\%) occurs with an interval of < 24 months after the preceding birth [8].

Various studies have identified determinants of maternal high-risk fertility behavior that are associated with anemia among women [9-12]. Previous studies have reported that high parity and short intervals between pregnancies were significant predictors of anemia among women [11, 12]. A study in India found that early childbearing, before 18 years of age, is negatively associated with anemia level [9]. Another study from the United States also found that pregnant women aged 35 and older were more likely to experience medical complications including anemia compared to women less than 35-year-old [10].

The majority of studies have assessed a subset of maternal high-risk fertility behavior individually. A few studies analyzed outcomes associated with the combined influence of maternal high-risk fertility behaviors $[13,14]$. Yet, such studies are limited in the African context. The development of effective prevention programs requires a better understanding of the individual and combined influences of maternal high-risk fertility behavior on anemia. The objective of the present study, therefore, was to examine the association between maternal high-risk fertility behavior and anemia among women of reproductive age in Ethiopia. We hypothesized that women exposed to maternal high-risk fertility behavior would be more likely to have anemia.

\section{Methods}

\section{Data sources}

A secondary data analysis was conducted using the 2016 Ethiopia Demographic and Health Survey (EDHS) [15]. The EDHS was conducted under the auspices of the Federal Ministry of Health (FMoH) and the Ethiopian Public Health Institute (EPHI), implemented by the Central Statistical Agency (CSA) and supported by ICF International, USAID, UNICEF, the World Bank, United Nation Population Fund (UNFPA) and UN Women [15].

The EDHS collected information from a nationally representative sample including both men and women to provide up-to-date estimates of demographic and health indicators. Data were collected using a probability-based two-stage stratified random sampling design. Data collection took place over a 5.5month period from January to June 2016. A detailed information on the methodology is available in the EDHS report [15].

\section{Study population and sample size}


The sampling frame for the current study consisted of 10640 women aged 15-49 years who undergone anemia testing. After excluding women with missing data on high risk fertility behavior $(n=1742)$ or any of the other covariates assessed in the current study ( $n=3099), 5799$ women were retained for the final analysis.

\section{Study variables}

Outcome of Interest: Anemia status

Anemia status of women aged 15-49 years was the outcome of interest in the current study. Anemia cutoff points used in the EDHS were those recommended by WHO. For non-pregnant women, any anemia was defined as $\mathrm{Hb}<12 \mathrm{~g} / \mathrm{dl}$, and for pregnant women as $<11 \mathrm{~g} / \mathrm{dl}$ [16]. Blood samples were taken from a finger prick and analyzed using a HemoCue analyzer. Hemoglobin levels were adjusted for cigarette smoking and altitude. Detailed procedures are explained elsewhere [15]. Anemia was used as a dichotomous variable (no, yes) instead of using a continuous hemoglobin concentration.

Exposure variable: Maternal high-risk fertility behavior

The exposure variable of the current study was maternal high-risk fertility behavior. The definition of highrisk fertility behavior adopted by the 2016 EDHS was applied [15]. High-risk fertility behavior was constructed using four different variables; (i) mother aged < 18 years at the time of delivery; (ii) mother aged > 34 years at the time of delivery; (iii) mother of a child born after a short birth interval (<24 months); and (iv) mother of high parity ( $>3$ children). The presence of one of the four conditions was termed a single high-risk fertility category. Combinations of two or more conditions were referred to as multiple high-risk category.

Three exposure variables were used for the current analysis: (i) any high-risk fertility behavior vs. none; (ii) exposure to different categories of high-risk fertility behaviors v. none (categorized as exposure to single high-risk category vs. none and multiple high-risk categories vs. none); and (iii) the specific types of highrisk fertility behaviors v. none.

\section{Covariates:}

Several variables that are theoretically and empirically linked to anemia $[6,7]$ were included in the current analysis such as: maternal age (15-24, 25-34, 35-49), education (no education, primary, secondary or higher), occupation (no, yes), residence (urban, rural), number of household members $(1-4,5-6, \geq 7)$, wealth index (poor, middle, rich), religion (non-Muslim, Muslim), body mass index (underweight, normal, overweight/ obese), current use of contraception (none, hormonal, barrier, physiological methods), pregnancy intention (intended, unintended), type of delivery (normal, cesarean), iron taken during pregnancy (no, yes) and maternal decision-making autonomy.

The household wealth index was used as an indicator to estimate the poverty-wealth status of households in the EDHS. It was calculated based on ownership of selected assets, such as televisions 
and bicycles, materials used for housing construction, and types of water source and sanitation facilities. The household population was then divided into five groups: first quintile (poorest), second quintile (poorer), third quintile (middle class), fourth quintile (richer), and fifth quintile (richest) [15]. In the current study, women were classified as poor if they belonged to the first or second wealth quintile, middle if they belonged to the third quantile, and rich if they belonged to fourth and fifth quintile.

Body mass index was defined as weight in $\mathrm{kg}$ divided by the square of height in $\mathrm{m}$. Body mass index categories were underweight ( $<18.5)$, normal $(18.5-24.9)$ and overweight/obese $(\geq 25)$. Contraceptive methods that include pills, injections and implants were categorized as hormonal methods. IUD, condoms and female sterilization were classified as barrier methods. IUD was considered as a barrier method due to lack of data on the type of IUD (i.e. copper and hormonal IUDs). Physiological methods included periodic abstinence, withdrawal, lactational amenorrhea (LAM) and standard days method (SDM).

Women's decision-making autonomy was measured by women's participation in household decision making. Women were considered to participate in household decisions if they make decisions alone or jointly with their husband in all three of the following areas: (i) the woman's own health care, (ii) major household purchases, and (iii) visits to the woman's family or relatives [15].

Frequency distribution and descriptive statistics (mean \pm standard deviation) were used to describe the characteristics of the study participants. Bivariate analysis using Rao-Scott Chi-Square test was performed to analyze the study participants according to their anemia status and high-risk fertility behavior. Three fully adjusted logistic regression models were created to analyze anemia status and each model contained a different fertility risk predictor (any vs. no risk; separate effects of single high-risk, multiple high-risk vs. no risk; specific types of high-risk vs. no risk).

Pairwise interactions between high-risk fertility behavior and each covariate were performed to examine differences in the relationship between high-risk fertility behavior and anemia status across different categories of covariates. There was a significant interaction between residence and high-risk fertility behavior on anemia status. Multivariable adjusted logistic regression models were performed to examine the independent association of high-risk fertility behavior on anemia status stratified by residence. All the covariates were entered simultaneously into all of the regression models.

Since the sampling design of EDHS was complex, sample weight (weighted frequency and weighted percentage) was used for all analysis to give accurate estimates for the population parameters.

Statistical testing was performed using SAS University Edition for Windows (SAS Institute Inc., Cary, NC, USA.). Two-tailed $p$ value $<0.05$ was considered statistically significant.

\section{Ethical considerations}

The EDHS received government permission, used informed consent and assured participants of confidentiality. The data was downloaded after the purpose of the study was justified and approved by the DHS program. The current study was considered exempt from a full review because it was based on 
an anonymous public use of a secondary dataset with unidentifiable information on the survey participants.

\section{Results}

Across the studied sample, $28.7 \%$ had anemia and $71.4 \%$ experienced high-risk fertility behaviors; with $43.1 \%$ falling into a single high-risk category and $28.3 \%$ falling into a multiple high-risk category. The mean age of the study participants was $30.76 \pm 0.16$ years, more than two-thirds of them $(69.9 \%)$ had no formal education and the majority $(90.3 \%)$ were rural residents. Other characteristics of the study participants are demonstrated in Table 1. Rural residence, poor wealth index, being Muslim, underweight and experiencing high-risk fertility behavior were significantly associated with anemia. While higher education, currently-working, hormonal contraceptive use and iron supplementation during pregnancy were inversely associated with occurrence of anemia (Table 1). All the covariates evaluated in the current study were found to significantly affect the potential for a high-risk birth, except occupation and body mass index (Table 2).

In the multivariable model, there was a significant interaction between place of residence and high-risk fertility behavior on anemia status among women. Table 4 presents the association between high-risk fertility behavior and anemia stratified by the type of place of residence. In both urban and rural areas, women with any high-risk category were significantly more likely to have anemia than women not in any high-risk category. However, the association was stronger among women residing in urban areas (AOR: 2.68; $95 \% \mathrm{Cl}, 1.26-5.67$ for urban residents and AOR: $1.27 ; 95 \% \mathrm{Cl}, 1.01-1.61$ for rural residents). Single high-risk category was significantly associated with the likelihood of anemia among urban women only (AOR: $2.65 ; 95 \% \mathrm{Cl}, 1.20-5.83$ ), while multiple high-risk category was found to significantly increase the odds of anemia among both urban (AOR: $2.82 ; 95 \% \mathrm{Cl}, 1.14-6.95$ ) and rural (AOR: $1.56 ; 95 \% \mathrm{Cl}, 1.11-$ 2.19) women (Table 4), although the association was stronger among women residing in urban areas.

\section{Discussion}

In a nationally representative sample of Ethiopian women of childbearing age, place of residence moderated the association between high-risk fertility behavior and anemia. This association is independent of potential confounders including maternal age, education, occupation, number of household members, wealth index, religion, BMI, current use of contraception, pregnancy intention, type of delivery, receipt of iron supplement during pregnancy and maternal decision-making autonomy.

In the current study, more than one-quarter of Ethiopian women of reproductive age were anemic. With reference to the WHO cutoff points [2], the magnitude indicates moderate public heath significance of anemia in Ethiopia. Anemia is a multi-causal problem originating from both individual and community levels. The cultural contexts of the community in which individuals live influence their dietary behavior, such as food taboo. Food taboo prohibits eating certain food items most of which are nutritious, resulting in poor nutritional outcomes [17]. In Ethiopia, several studies reported the existence of pervasive 
pregnancy-related food taboos and myths, which might be contributing to the burden of maternal anemia in the country $[18,19]$. Ethiopian pregnant women avoid certain food items for a range of reasons; some associated with pregnancy outcome and birthing process and others to avoid undesirable aesthetic features in the baby [19]. Furthermore, two-thirds of Ethiopian population lives in malaria transmission areas [20]. Pregnancies in women living in malaria endemic regions are associated with high frequency and density of parasitemia, with high rates of maternal morbidity including anemia [21].

The current prevalence was comparable with other studies conducted in neighboring countries such as Zimbabwe (27\%) [22] and Uganda (32\%) [23]. But our figure was lower than the prevalence of anemia reported in Tanzania (45\%) [24] and Senegal (54\%) [25]. This discrepancy might be due to variations in health care provision, different socio-economic, cultural and dietary patterns throughout the regions.

Nearly three-quarters of Ethiopian women experienced at least one of the high-risk fertility behaviors. It is considered to be alarmingly the highest figure when compared to other developing countries such as Afghanistan (65\%) [26] and Tanzania (55\%) [24]. Among Ethiopian population, traditional norms and values that have perpetuated a high fertility norm coupled with the high rate of child mortality are escalating the need to have births in closer intervals, in early and late reproductive ages, and in large numbers [27].

The current study highlighted the significant burden of high-risk fertility behavior on anemia occurrence among Ethiopian women. These findings were consistent with a Bangladeshi study, reporting an association between high-risk fertility behaviors and women's nutritional disadvantages [13]. Several mechanisms through which high-risk fertility behaviors could be related to increased likelihood for anemia have been identified previously [28-32]. Short inter-pregnancy intervals worsen mother's nutritional status because of inadequate time to recover from the physiological stresses imposed by the previous pregnancy thus increasing the risk of maternal depletion syndrome. This results in depletion of maternal nutrient stores and anemia [28]. The recovery is also affected by breastfeeding. The increased requirements for breastfeeding in some ways tax the mother's body even more than pregnancy, with increases in energy needs and nutrients [29]. Additionally, parity was significantly associated with anemia. This could be attributable to the loss of iron and other nutrients during repeated pregnancies and also the possibility of sharing of resources with the fetus [30]. Another report suggested high susceptibility to hemorrhage among women with high parity [31]. Early childbirth has been also identified as a risk factor of anemia due to depleted iron stores that occurred during the adolescent growth spurt [32].

Rural residents are more likely to have challenges in accessing health services facilities that result in a higher frequency of health problems [33]. However, the current study showed that the relationship between high-risk fertility behavior and anemia status was stronger among urban women compared to their rural counterparts. Such differences might be attributed to the different types of food consumed by the urban and rural women. Adamu et al. [34] and Heidkamp et al. [35] suggested that rural residents are more likely to seasonally access and consume iron-rich fruits and vegetables such as leafy green 
vegetables at low or no cost, compared to those living in urban areas. Our finding could also be explained by the frequent unplanned migration from rural areas to the cities in recent decades, resulting in people living under poor conditions in the slums of the country's metropolitan areas [36]. Furthermore, the quality of life and health of the urban population, especially in large cities, is susceptible to nutritional risks due to the accelerated pace of life and the higher availability of industrialized nutrient-poor food [37, 38].

The main strength of the current study is that the analyzed data were from a large, randomly selected nationally-representative sample of Ethiopian women of reproductive age and collected by accredited and reliable official entities using well-tested biomarkers and methodology [15]. The large sample size provided the study with good statistical power. The dataset also contained several potential confounding factors for the risk of anemia that was used for adjustment in the current analysis. However, findings from the current study should be interpreted in light of the following limitations. The cross-sectional design of the EDHS limits the causality pathway between high-risk fertility behavior and anemia status. EDHS is also susceptible to recall and social desirability bias, since it is based on self-reporting.

\section{Conclusion}

Despite these limitations, our study brought out significant findings that could serve as a basis for reducing the likelihood of anemia among women of reproductive age in Ethiopia. Our findings suggest the need for context-specific strategies and interventions to prevent anemia. Community-based reproductive health promotion campaigns, reaching women of childbearing age, could raise their awareness about the adverse outcomes of risky fertility behaviors on women's health and nutritional status. Our findings also highlight future areas of interest for additional studies in other low-income settings where maternal anemia is prevalent.

\section{Declarations}

Author Contributions: NF and ZH contributed to the study conception, design and analysis. The first draft of the manuscript was written by NF. ZH and GI critically revised the manuscript. All authors read and approved the final manuscript.

Conflict of interest: The authors declare that they have no conflict of interest.

Acknowledgements: The authors are grateful to DHS for providing access to data for the 2016 Ethiopia Demographic and Health Survey.

Funding sources: This research did not receive any specific grant from funding agencies in the public, commercial, or not-for-profit sectors.

\section{References}


1. Osungbade KO, Oladunjoye AO. Anaemia in Developing Countries: Burden and Prospects of Prevention and Control, Anemia, Donald S. Silverberg, IntechOpen; 2012. DOI: 10.5772/29148.

2. WHO. The global prevalence of anaemia in 2011. Geneva: World Health Organization. 2015.

3. Tolentino K, Friedman J. An update on anemia in less developed countries. Am J Trop Med Hyg. 2007;77(1):44-51. PMID: 17620629.

4. Khaskheli M, Baloch S, Sheeba A, Baloch S, Khaskheli F. Iron deficiency anaemia is still a major killer of pregnant women. Pak J Med Sci. 2016;32(3):630-634. Doi: 10.12669/pjms.323.9557.

5. WHO. Global nutrition targets 2025: anaemia policy brief. Geneva: World Health Organization (WHO/NMH/NHD/14.4;

http://apps.who.int/iris/bitstream/10665/148556/1/WHO_NMH_NHD_14.4_eng.pdf?ua=1, accessed 18 December 2018). 2014.

6. Asres $Y$, Yemane T, Gedefaw L. Determinant Factors of Anemia among Nonpregnant Women of Childbearing Age in Southwest Ethiopia: A Community Based Study. Int Sch Res Notices. 2014;2014. Doi: $10.1155 / 2014 / 391580$.

7. Sadeghian M, Fatourechi A, Lesanpezeshki M, Ahmadnezhad E. Prevalence of anemia and correlated factors in the reproductive age women in rural areas of tabas. J Family Reprod Health. 2013;7(3):139-144. PMID: 24971116.

8. Central Statistical Agency/Ethiopia, ICF International. Ethiopia Demographic and Health Survey 2011. Addis Ababa, Ethiopia and Calverton, Maryland, USA: Central Statistical Agency and ICF International, 2012.

9. Goli S, Rammohan A, Singh D. The effect of early marriages and early childbearing on women's nutritional status in India. Matern Child Health J. 2015;19:1864-1880. Doi: 10.1007/s10995-0151700-7.

10. Grotegut C, Chisholm C, Johnson L, Brown H, Heine R, James A. Correction: Medical and Obstetric Complications among Pregnant Women Aged 45 and Older. PLOS ONE 2016;11(3): e0151307. Doi: 10.1371/journal.pone.0151307.

11. Kavak E, Kavak S. The association between anemia prevalence, maternal age and parity in term pregnancies in our city. Perinatal Journal. 2017;25(1):6-10. Doi: 10.2399/prn.17.0251002.

12. Srivastava A, Mahmood S, Mishra P, Shrotriya V. Correlates of maternal health care utilization in rohilkhand region, India. Ann Med Health Sci Res. 2014;4(3):417-425. Doi: 10.4103/21419248.133471.

13. Rahman $M$, Islam $M$, Haque $S$, et al. Association between high-risk fertility behaviours and the likelihood of chronic undernutrition and anaemia among married Bangladeshi women of reproductive age. Public Health Nutr. 2017;20(2):305-314. Doi: 10.1017/S136898001600224X.

14. Rahman M, Haque S, Zahan S, et al. Maternal high-risk fertility behavior and association with chronic undernutrition among children under age $5 \mathrm{y}$ in India, Bangladesh, and Nepal: Do poor children have a higher risk? Nutrition. 2018;49:32-40. Doi: 10.1016/j.nut.2017.10.001. 
15. Central Statistical Agency (CSA) /Ethiopia, ICF. Ethiopia Demographic and Health Sruvey 2016. Addis Ababa, Ethiopia and Rockville, Maryland, USA: CSA and ICF, 2016.

16. WHO. Haemoglobin concentrations for the diagnosis of anaemia and assessment of severity. Vitamin and Mineral Nutrition Information System. Geneva, World Health Organization, (WHO/NMH/NHD/MNM/11.1) (http://www.who.int/vmnis/indicators/haemoglobin. pdf, accessed [20 Novemeber 2018]). 2011.

17. Meyer-Rochow V. Food taboos: their origins and purposes. J Ethnobiol Ethnomed. 2009;5(18):18. Doi:10.1186/1746-4269-5-18

18. Mohammed SH, Taye H, Larijani B, Esmaillzadeh A. Food taboo among pregnant Ethiopian women: magnitude, drivers, and association with anemia. Nutrition Journal. 2019;18(19). Doi: 10.1186/s12937-019-0444-4

19. Vasilevski V, Carolan-Olah M. Food taboos and nutrition-related pregnancy concerns among Ethiopian women. J Clin Nurs. 2016;25(19-20):3069-3075. Doi: 10.1111/jocn.13319

20. Alemu K, Worku A, Berhane Y. Malaria infection has spatial, temporal, and spatiotemporal heterogeneity in unstable malaria transmission areas in northwest Ethiopia. PloS one. 2013;8(11):e79966. Doi: 10.1371/journal.pone.0079966

21. Uneke CJ. Impact of placental Plasmodium falciparum malaria on pregnancy and perinatal outcome in sub-Saharan Africa: I: introduction to placental malaria. Yale J Biol Med. 2007;80(2):39-50. PMCID: PMC2140183

22. Zimbabwe National Statistics Agency (ZIMSTAT), ICF International. Zimbabwe Demographic and Health Survey 2015: Final Report Rockville, Maryland, USA: ZIMSTAT and ICF International, 2016.

23. Uganda Bureau of Statistics (UBOS), ICF. 2016 Uganda Demographic and Health Survey Key Findings. Kampala, Uganda, and Rockville, Maryland, USA: UBOS and ICF, 2017.

24. Ministry of Health, Community Development, Gender, Elderly and Children - MoHCDGEC/Tanzania Mainland, Ministry of Health - MoH/Zanzibar, National Bureau of Statistics - NBS/Tanzania, Office of Chief Government Statistician - OCGS/Zanzibar, and ICF. 2016. Tanzania Demographic and Health Survey and Malaria Indicator Survey (TDHS-MIS) 2015-16. Dar es Salaam/Tanzania: MoHCDGEC, MoH, NBS, OCGS, and ICF.

25. Agence Nationale de la Statistique et de la Démographie ANSD/Senegal, ICF. Enquête Continue du Sénégal, Cinquième Phase 2017 : Rapport de synthèse. Rockville, Maryland, USA: ANSD et ICF, 2018.

26. Central Statistics Organization/Afghanistan, Ministry of Public Health, ICF. Afghanistan Demographic and Health Survey 2015. Kabul, Afghanistan: Central Statistics Organization, 2017.

27. Gurmu E, Dejene T. Correlates of High Risk Fertility Behaviour in Ethiopia: A Multilevel Analysis of the 2011 Ethiopian Demographic and Health Survey Data. Journal of Health, Medicine and Nursing. 2017;39:86-95

28. King J. The risk of maternal nutritional depletion and poor outcomes increases in early or closely spaced pregnancies. J Nutr. 2003;133(5):1732S-1736S. Doi: 10.1093/jn/133.5.1732S. 
29. Dewey K, Cohen R. Does birth spacing affect maternal or child nutritional status? A systematic literature review. Matern Child Nutr. 2007;3:151-173. Doi: 10.1111/j.1740-8709.2007.00092.x.

30. Alene K, Dohe A. Prevalence of Anemia and Associated Factors among Pregnant Women in an Urban Area of Eastern Ethiopia. Anemia. 2014;2014. Doi: 10.1155/2014/561567.

31. Aliyu M, Jolly P, Ehiri J, Salihu H. High parity and adverse birth outcomes: exploring the maze. Birth. 2005;32(1):45-59. Doi: 10.1111/j.0730-7659.2005.00344.x.

32. Hoque M, Kader S, Hoque E, C. M. Prevalence of anaemia in pregnancy at Greytown, South Africa. Trop J Obstet Gynaecol. 2006;23(1):3-7. Doi: 10.4314/tjog.v23i1.14554.

33. World Health Organization. Worldwide prevalence of anaemia 1993-2005:WHO global database on anaemia. Geneva, Switzerland.

http://apps.who.int/iris/bitstream/10665/43894/1/9789241596657_eng.pdf . 2008.

34. Adamu A, Crampin A, Kayuni N, et al. Prevalence and risk factors for anemia severity and type in Malawian men and women: urban and rural differences. Popul Health Metr. 2017;15(2):12. Doi: 10.1186/s12963-017-0128-2

35. Heidkamp R, Ngnie-Teta I, Ayoya M, et al. Predictors of anemia among haitian children aged 6 to 59 months and women of childbearing age and their implications for programming. Food Nutr Bull. 2013;34(4):462-479. Doi: 10.1177/156482651303400411.

36. Davis M. Planet of Slums. London: Verso Publishers; 2006.

37. ZacarÃas I, RodrÃguez O, Lera L, Hill D, Domper RA, González A. Vegetables and fruits consumption in health centres and supermarkets in the Chilean metropolitan region: 5 a day program. Rev chil nutr. 2009;36(2):159-168. Doi: 10.4067/S0717-75182009000200008.

38. Ghosh S, Shah D. Nutritional problems in urban slum children. Indian Pediatr. 2004;41(7):682-696. PMID: 15297683.

\section{Tables}

Table (1): Characteristics of the study participants by anemia status $(n=5799)$ 


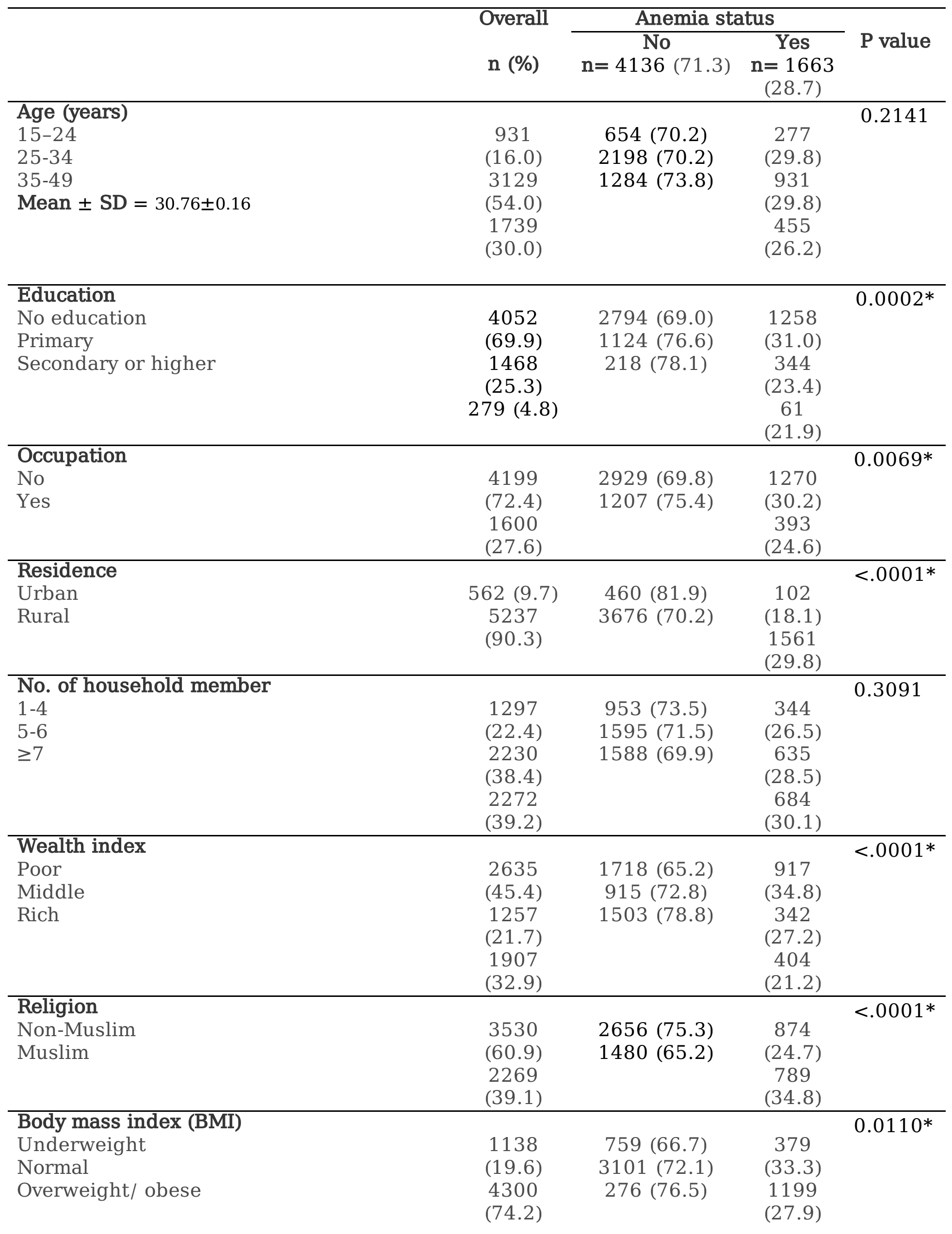




\begin{tabular}{|c|c|c|c|c|}
\hline & & & (23.5) & \\
\hline $\begin{array}{l}\text { Current use of contraception } \\
\text { None } \\
\text { Hormonal (pills, injections, implants) } \\
\text { Barrier (IUD, condoms, \sterilization) } \\
\text { Physiological \# }\end{array}$ & $\begin{array}{c}3770 \\
(65.0) \\
1856 \\
(32.0) \\
134(2.3) \\
39(0.7)\end{array}$ & $\begin{array}{l}2527(67.0) \\
1488(80.2) \\
88(65.7) \\
33(84.6)\end{array}$ & $\begin{array}{c}1243 \\
(33.0) \\
368 \\
(19.8) \\
46 \\
(34.3) \\
6(15.4)\end{array}$ & $<.0001 *$ \\
\hline $\begin{array}{l}\text { Pregnancy intention } \\
\text { Intended } \\
\text { Unintended }\end{array}$ & $\begin{array}{l}4173 \\
(72.0) \\
1626 \\
(28.0) \\
\end{array}$ & $\begin{array}{l}2935 \text { (70.3) } \\
1201(73.9)\end{array}$ & $\begin{array}{l}1238 \\
(29.7) \\
425 \\
(26.1) \\
\end{array}$ & 0.0768 \\
\hline $\begin{array}{l}\text { Type of delivery } \\
\text { Normal } \\
\text { CS }\end{array}$ & $\begin{array}{c}5700 \\
(98.3) \\
99(1.7)\end{array}$ & $\begin{array}{c}4058(71.2) \\
78(78.8)\end{array}$ & $\begin{array}{c}1642 \\
(28.8) \\
21 \\
(21.2) \\
\end{array}$ & 0.1661 \\
\hline $\begin{array}{l}\text { During pregnancy, mother given or bought } \\
\text { iron tablets } \\
\text { No } \\
\text { Yes }\end{array}$ & $\begin{array}{l}3450 \\
(59.5) \\
2349 \\
(40.5) \\
\end{array}$ & $\begin{array}{l}2371(68.7) \\
1765(75.1)\end{array}$ & $\begin{array}{c}1079 \\
(31.3) \\
584 \\
(24.9) \\
\end{array}$ & $0.0004 *$ \\
\hline $\begin{array}{l}\text { Maternal decision-making autonomy, no. of } \\
\text { aspects ** } \\
0 \\
1 \\
2 \\
3\end{array}$ & $\begin{array}{c}662 \\
(11.4) \\
423(7.3) \\
712(12.3) \\
4002 \\
(69.0)\end{array}$ & $\begin{array}{c}445(67.2) \\
295(69.8) \\
500(70.2) \\
2896(72.4)\end{array}$ & $\begin{array}{l}217 \\
(32.8) \\
128 \\
(30.2) \\
212 \\
(29.8) \\
1106 \\
(27.6) \\
\end{array}$ & 0.3185 \\
\hline $\begin{array}{l}\text { Any high-risk category } \\
\text { No } \\
\text { Yes }\end{array}$ & $\begin{array}{l}1658 \\
(28.6) \\
4141 \\
(71.4)\end{array}$ & $\begin{array}{l}1266(76.4) \\
2870(69.3)\end{array}$ & $\begin{array}{l}392 \\
(23.6) \\
1271 \\
(30.7)\end{array}$ & $0.0003^{*}$ \\
\hline $\begin{array}{l}\text { Types of high-risk category } \\
\text { No risk } \\
\text { Single high-risk category } \\
\text { Mother age }<18 \text { y at birth } \\
\text { Mother age }>34 \text { y at birth } \\
\text { Birth interval < } 24 \text { months } \\
\text { Birth order }>3 \\
\text { Multiple high-risk category }\end{array}$ & $\begin{array}{c}1658 \\
(28.6) \\
2499 \\
(43.1) \\
219(8.8) \\
44(1.8) \\
333 \\
(13.3) \\
1903 \\
(76.1)\end{array}$ & $\begin{array}{l}1266(76.4) \\
1731(69.3) \\
158(72.1) \\
35(79.5) \\
225(67.6) \\
1313(69.0) \\
1139(69.4)\end{array}$ & $\begin{array}{c}392 \\
(23.6) \\
768 \\
(30.7) \\
61 \\
(27.9) \\
9(20.5) \\
108 \\
(32.4) \\
590 \\
(31.0)\end{array}$ & $0.0012 *$ \\
\hline
\end{tabular}


Mother age $<18$ y at birth + birth interval $<$ 24 months

Mother age $>34$ y at birth + birth interval < 24months

Mother age $>34 y$ at birth + Birth order $>3$

Mother age $>34$ y at birth + birth interval $<$ 24 months + Birth order $>3$

Birth interval $<24$ months + Birth order $>3$
1642

(28.3)

$20(1.2)$

$1(0.1)$

$982(59.8)$

$160(9.7)$

479

(29.2)
503

(30.6)

$730(74.3)$

$4(20.0)$

$102(63.7)$

$291(60.8)$

$0(0.0)$

252

58

$* P<0.05$

** Aspects of family decisions where a woman participated alone or jointly in the decision making in determining own health care, making large household purchases and visiting family or relatives.

\# Physiological methods included periodic abstinence, withdrawal, lactational amenorrhea (LAM) and standard days method (SDM)

Table (2): Characteristics of the study participants by high-risk fertility behavior $(n=5799)$ 


\begin{tabular}{|c|c|c|c|c|}
\hline & & h-risk fertilit & behavior, $\mathrm{n}$ & \\
\hline & $\begin{array}{c}\text { No risk } \\
\mathrm{n}=1658 \\
(28.6)\end{array}$ & $\begin{array}{l}\text { Single risk } \\
\mathrm{n}=2499 \\
(43.1)\end{array}$ & $\begin{array}{c}\text { Multiple } \\
\text { risk } \\
\mathrm{n}=1642 \\
(28.3) \\
\end{array}$ & $\mathrm{P}$ value \\
\hline $\begin{array}{l}\text { Age (years) } \\
15-24 \\
25-34 \\
35-49\end{array}$ & $\begin{array}{l}479(51.4) \\
1109 \\
(35.4) \\
70(4.0)\end{array}$ & $\begin{array}{c}403(43.3) \\
1662(53.1) \\
434(25.0)\end{array}$ & $\begin{array}{c}49(5.3) \\
358(11.5) \\
1235(71.0)\end{array}$ & $<.0001 *$ \\
\hline $\begin{array}{l}\text { Education } \\
\text { No education } \\
\text { Primary } \\
\text { Secondary or higher }\end{array}$ & $\begin{array}{l}898(22.2) \\
574(39.1) \\
186(66.7)\end{array}$ & $\begin{array}{c}1828(45.1) \\
605(41.2) \\
66(23.6)\end{array}$ & $\begin{array}{c}1326(32.7) \\
289(19.7) \\
27(9.7)\end{array}$ & $<.0001 *$ \\
\hline $\begin{array}{l}\text { Occupation } \\
\text { No } \\
\text { Yes }\end{array}$ & $\begin{array}{c}1148 \\
(27.3) \\
510(31.9)\end{array}$ & $\begin{array}{c}1849(44.1) \\
650(40.6)\end{array}$ & $\begin{array}{c}1202(28.6) \\
440(27.5)\end{array}$ & 0.0940 \\
\hline $\begin{array}{l}\text { Residence } \\
\text { Urban } \\
\text { Rural }\end{array}$ & $\begin{array}{c}299(53.2) \\
1359 \\
(26.0)\end{array}$ & $\begin{array}{c}157(27.9) \\
2342(44.7)\end{array}$ & $\begin{array}{c}106(18.9) \\
1536(29.3)\end{array}$ & $<.0001^{*}$ \\
\hline $\begin{array}{l}\text { No. of household member } \\
1-4 \\
5-6 \\
\geq 7\end{array}$ & $\begin{array}{l}794(61.2) \\
756(33.9) \\
108(4.7)\end{array}$ & $\begin{array}{l}425(32.8) \\
1023(45.9) \\
1051(46.3)\end{array}$ & $\begin{array}{c}78(6.0) \\
451(20.2) \\
1113(49.0)\end{array}$ & $<.0001 *$ \\
\hline $\begin{array}{l}\text { Wealth index } \\
\text { Poor } \\
\text { Middle } \\
\text { Rich }\end{array}$ & $\begin{array}{l}631(24.0) \\
346(27.5) \\
681(35.7)\end{array}$ & $\begin{array}{l}1202(45.6) \\
564(44.9) \\
733(38.4)\end{array}$ & $\begin{array}{l}802(30.4) \\
347(27.6) \\
493(25.9)\end{array}$ & $<.0001 *$ \\
\hline $\begin{array}{l}\text { Religion } \\
\text { Non-Muslim } \\
\text { Muslim }\end{array}$ & $\begin{array}{c}1145 \\
(32.4) \\
513(22.6)\end{array}$ & $\begin{array}{l}1425(40.4) \\
1074(47.3)\end{array}$ & $\begin{array}{l}960(27.2) \\
682(30.1)\end{array}$ & $<.0001 *$ \\
\hline $\begin{array}{l}\text { Body mass index (BMI) } \\
\text { Underweight } \\
\text { Normal } \\
\text { Overweight/ obese }\end{array}$ & $\begin{array}{c}328(28.8) \\
1202 \\
(28.0) \\
128(35.5) \\
\end{array}$ & $\begin{array}{c}487(42.8) \\
1876(43.6) \\
136(37.7)\end{array}$ & $\begin{array}{l}323(28.4) \\
1222(28.4) \\
97(26.8)\end{array}$ & 0.3624 \\
\hline $\begin{array}{l}\text { Current use of contraception } \\
\text { None } \\
\text { Hormonal (pills, implants, injections) } \\
\text { Barrier (IUD, condoms, \sterilization) } \\
\text { Physiological \# }\end{array}$ & $\begin{array}{c}938(24.9) \\
659(35.5) \\
47(35.1) \\
14(35.9)\end{array}$ & $\begin{array}{l}1651(43.8) \\
775(41.8) \\
62(46.3) \\
11(28.2)\end{array}$ & $\begin{array}{l}1181(31.3) \\
422(22.7) \\
25(18.6) \\
14(35.9)\end{array}$ & $<.0001^{*}$ \\
\hline $\begin{array}{l}\text { Pregnancy intention } \\
\text { Intended } \\
\text { Unintended }\end{array}$ & $\begin{array}{c}1323 \\
(31.7) \\
335 \quad(20.6) \\
\end{array}$ & $\begin{array}{c}1801(43.2) \\
698(42.9)\end{array}$ & $\begin{array}{c}1049(25.1) \\
593(36.5)\end{array}$ & $<.0001 *$ \\
\hline $\begin{array}{l}\text { Type of delivery } \\
\text { Normal } \\
\text { CS }\end{array}$ & $\begin{array}{c}1596 \\
(28.0) \\
62(62.6) \\
\text { ge } 15 / 17\end{array}$ & $\begin{array}{c}2477(43.5) \\
22(22.2)\end{array}$ & $\begin{array}{c}1627(28.5) \\
15(15.2)\end{array}$ & $<.0001 *$ \\
\hline
\end{tabular}




\begin{tabular}{|c|c|c|c|c|}
\hline \multicolumn{4}{|l|}{$\begin{array}{l}\text { During pregnancy, mother given or } \\
\text { bought iron tablets }\end{array}$} & \multirow[t]{3}{*}{$<.0001^{*}$} \\
\hline No & $863(25.0)$ & 1505 (43.6) & $1082(31.4)$ & \\
\hline Yes & 795 (33.9) & $994(42.3)$ & $560(23.8)$ & \\
\hline $\begin{array}{l}\text { Maternal decision-making autonomy, no. } \\
\text { of aspects ** }\end{array}$ & & & & $0.0202 *$ \\
\hline 0 & $162(24.5)$ & 255 (38.5) & $245(37.0)$ & \\
\hline 1 & $129(30.5)$ & 184 (43.5) & $110(26.0)$ & \\
\hline 2 & 169 (23.7) & $336(47.2)$ & 207 (29.1) & \\
\hline 3 & $\begin{array}{l}1198 \\
(29.9)\end{array}$ & 1724 (43.1) & $1080(27)$ & \\
\hline Anemia status & & & & $0.0012 *$ \\
\hline No & 1266 & 1731 (41.9) & 1139(27.5) & \\
\hline Yes & $\begin{array}{c}(30.6) \\
392(23.6) \\
\end{array}$ & 768 (46.2) & $503(30.2)$ & \\
\hline
\end{tabular}

$* P<0.05$

** Aspects of family decisions where a woman participated alone or jointly in the decision making in determining own health care, making large household purchases and visiting family or relatives.

\# Physiological methods included periodic abstinence, withdrawal, lactational amenorrhea (LAM) and standard days method (SDM)

Table (3): AOR for association between different patterns of high-risk fertility behavior among women and anemia status $(\mathrm{n}=5799)$

High-risk fertility behavior anemia status, AOR (95\%

CI)

AOR

$95 \% \mathrm{CI}$

\begin{tabular}{|c|c|c|c|}
\hline $\begin{array}{l}\text { Any high-risk } \\
\text { No } \\
\text { Yes }\end{array}$ & $\begin{array}{l}1.00 \\
1.38 *\end{array}$ & 1.10 & 1.74 \\
\hline \multicolumn{4}{|l|}{ Types of high-risk } \\
\hline No risk & 1.00 & \multicolumn{2}{|c|}{ - } \\
\hline Single risk & $1.34 *$ & 1.07 & 1.68 \\
\hline Multiple risk & $1.67 *$ & 1.21 & 2.31 \\
\hline \multicolumn{4}{|l|}{ Specific types of high-risk } \\
\hline No risk & 1.00 & & \\
\hline Mother age $<18$ y at birth & 1.00 & 0.59 & 1.67 \\
\hline Mother age $>34$ y at birth & 0.97 & 0.35 & 2.74 \\
\hline Birth interval $<24$ months & 1.15 & 0.78 & 1.71 \\
\hline Birth order $>3$ & 1.04 & 0.86 & 1.26 \\
\hline Mother age $<18 \mathrm{y}$ at birth + birth interval $<24$ months & 0.59 & 0.10 & 3.62 \\
\hline Mother age $>34$ y at birth + birth interval $<24$ months & NA & \multicolumn{2}{|c|}{ NA } \\
\hline Mother age $>34 y$ at birth + Birth order $>3$ & 0.91 & 0.66 & 1.24 \\
\hline $\begin{array}{l}\text { Mother age }>34 \text { y at birth }+ \text { birth interval }<24 \text { months }+ \text { Birth } \\
\text { order }>3\end{array}$ & 1.45 & 0.89 & 2.34 \\
\hline Birth interval $<24$ months + Birth order $>3$ & $1.46 *$ & 1.09 & 1.97 \\
\hline
\end{tabular}

$* P<0.05$

AOR, adjusted odds ratio; CI, confidence interval

NA: Not calculated due to small sample size 
Models were adjusted for maternal age, education, occupation, residence, number of household members, wealth index, religion, BMI, current use of contraception, pregnancy intention, type of delivery, iron taken during pregnancy, maternal decision-making autonomy.

Table (4): AOR for association between different patterns of high-risk fertility behavior among women and anemia status according to residence $(n=5799)$

\begin{tabular}{|c|c|c|}
\hline \multirow[t]{2}{*}{ High-risk fertility behavior } & \multicolumn{2}{|c|}{ anemia status, AOR (95\% CI) } \\
\hline & Urban & Rural \\
\hline $\begin{array}{l}\text { Any high-risk } \\
\text { No } \\
\text { Yes }\end{array}$ & $2.68(1.26-5.67) *$ & $\begin{array}{c}1.00 \\
1.27(1.01-1.61) *\end{array}$ \\
\hline $\begin{array}{l}\text { Types of high-risk } \\
\text { No risk } \\
\text { Single risk } \\
\text { Multiple risk }\end{array}$ & $\begin{array}{c}1.00 \\
2.65(1.20-5.83) * \\
2.82(1.14-6.95) *\end{array}$ & $\begin{array}{c}1.00 \\
1.23(0.98-1.55) \\
1.56(1.11-2.19) *\end{array}$ \\
\hline
\end{tabular}

$* P<0.05$

AOR, adjusted odds ratio; CI, confidence interval

Models were adjusted for maternal age, education, occupation, residence, number of household members, wealth index, religion, BMI, current use of contraception, pregnancy intention, type of delivery, iron taken during pregnancy, maternal decision-making autonomy. 